Western University Scholarship@Western

1984

\title{
Asset Pricing with Capital Accumulation
}

Gregory W. Huffman

Follow this and additional works at: https://ir.lib.uwo.ca/economicsresrpt

Part of the Economics Commons

Citation of this paper:

Huffman, Gregory W.. "Asset Pricing with Capital Accumulation." Department of Economics Research Reports, 8404. London, ON: Department of Economics, University of Western Ontario (1984). 
ISBN : $\quad 0-7714-0511-1$

\section{RESEARCH REPORT 8404}

\section{ASSET PRICING WITH CAPITAL ACCUMULATION}

by

Greg Huffman

March, 1984

I would like to thank James Jordan, Thomas Sargent, Christopher Sims, and especially Neil Wallace for helpful advice. Any remaining errors are my own responsibility.

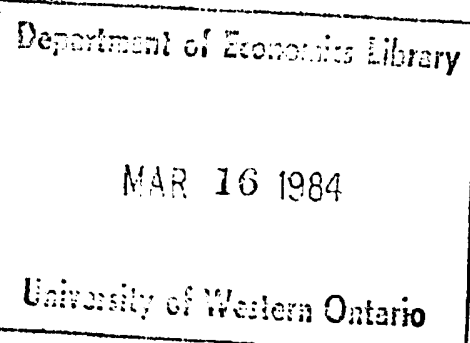




\section{INTRODUCTION}

A great deal of attention has been devoted recently to the study of the behavior of asset prices. One stylized fact produced from such work is the excessive volatility which asset prices, and in particular stock prices, tend to exhibit. This observation seems paradoxical, especially when it is viewed within the context of certain economic models.

Shiller [26] has studied what is known as the present value relation:

$$
P_{t}=\sum_{i=1}^{\infty} \gamma^{i} E_{t} d_{t+i} \quad(0<\gamma<1) \text {. }
$$

Here $P_{t}$ represents the real price of a stock, $d_{t}$ is the dividend paid in period (t) to the holder of the stock, $\gamma$ represents the constant discount factor, and $E_{t}$ is the expectational operator conditional on all information available at time t. Starting from expression (1), Shiller derived bounds on the variance of stock prices which were functions of the variance of dividends. However, these bounds were dramatically violated by the data. Thus, actual stock prices appear to be much too volatile to be consistent with (1). With this in mind, the only way to save the relation (1) would be to hypothesize that the real discount factor $(\gamma)$ may vary over time. However, Shiller suggests that the movements in $(\gamma)$ needed to make equation (1) hold identically seem implausibly high.

LeRoy and Porter [17] have also studied the relation (1). They show that the variance of the stock price $\left(P_{t}\right)$ should be bounded from above by the variance of the perfect foresight version of equation (1) (i.e., the perfect foresight consists of replacing $E_{t}\left(d_{t+k}\right)$ with $\left.d_{t+k}\right)$. However, this bound is also violated when LeRoy and Porter test it against various data sets.

Therefore, it would seem that equations which relate stock prices to dividends, which are discounted at a constant rate, have implications for the second moments 
of prices and dividends which are violated by the data. This in turn implies that a certain class of models, namely those which give rise to an asset pricing formula such as (1), seem to be contradicted by the data. However, the manner in which assets are priced cannot be regarded as robust with respect to different specifications of the physical environment. Equation (1) will hold only for an economy in which agents discount all future dividends at a constant rate. However, in a model in which infinitely lived agents maximize discounted lifetime utility, the rate at which future dividends are discounted is proportional to a ratio of marginal rates of substitution. The discounting of dividends at a constant rate would then imply that consumption should be constant or that utility is linear. However, if agents are risk averse and consumption exhibits variability, asset prices will not be governed by an equation of the form of (1). In an equilibrium mode1, variability in the rate at which future dividends are discounted should be related to consumption, which in turn is related to the dividends which are actually being discounted.

LeRoy and LaCivita [16] have recognized these points and have utilized a framework in which agents maximize discounted lifetime utility:

$$
\sum_{t=0}^{\infty} \beta^{t} U\left(c_{t}\right)
$$

where

$$
U\left(c_{t}\right)= \begin{cases}\frac{c_{t}^{1-A}-1}{1-A} & A>0, A \neq 1 \\ \ln \left(c_{t}\right) & A=1 .\end{cases}
$$

$A$ is the measure of relative risk aversion. The consumers' budget constraint is

$$
c_{t}+P_{t} x_{t} \leq x_{t-1}\left(P_{t}+r_{t}\right)
$$

where

$$
c_{t}=\text { consumption in period }(t) \text {, }
$$$$
x_{t}=\text { quantity of assets purchase by the consumer in period }(t) \text {. }
$$$$
\text { In equilibrium we have } x_{t}=x_{t+1}=1 \text { for all }(t) \text {, }
$$

$\mathbf{P}_{t}=$ price of the asset in period $(t)$,

$r_{t}=$ dividend paid by the asset in period $(t)$. 
They have found that, for a given distribution of dividends, stock price variability will be directly proportional to the degree of relative risk aversion exhibited by agents. This would indicate that the observed stock price variability may be accounted for by high levels of risk aversion on the part of consumers. Grossman and Shiller [5] attempted to explain the existence of high stock price variability by hypothesizing that consumption patterns exhibit enough variability to alter agents' marginal rates of substitution and thereby induce changes in the value of assets which yield dividends. They found that the observed behavior of stock prices can, to some extent, be explained by assuming a level of relative risk aversion in equation (2) of $A=4$. One may then conclude that the observed patterns in asset prices, dividends and aggregate consumption can be reconciled if we accept that agents possess a high degree of risk aversion. However, it is not clear that this is the answer to the anomaly because a value of 4 for the variable A would seem to be rather high in comparison with other estimates of this parameter. Hansen and Singleton [8], using different data than that used by Grossman and Shiller, ${ }^{1}$ have recently made estimates of A in equation (2) which were all between 0 and 1 . It should be stressed, however, that they merely undertook estimating the parameter A, and their objective was not to rationalize the volatility exhibited by stock prices.

Thus, in summary, we seek to confront the stylized fact that stock prices tend to be too volatile to be consistent with observed patterns in consumption, real interest rates, dividends, and existing estimates of individual risk aversion. Throughout the existing literature on asset pricing, one finds a class of models in use that have not been entirely successful in explaining all observed phenomena. An example of such a model would be that of Lucas [18]. In this paper Iucas assumes that infinitely lived agents seek to maximize the discounted sum of future utilities, as shown in equation (2), subject to the constraint that all asset markets are cleared (i.e., all assets are held at the equilibrium prices). Thus, 
an agent who has the option to buy an asset will find it in his or her best interest to forecast and valuate all future rentals or dividends yielded by the security. In most of these setups the equilibrium is repetitive in the sense that each period agents will choose to hold the same assets they held during the last period, although the security prices and consumption patterns may change over time. In short, agents will participate in the asset market the same way each period.

It is exactly this type of model which Grossman and Shiller have used in their attempt to explain this high stock price volatility. Therefore, in contrast to this, we propose to use the overlapping generations framework with two-period lived agents。 ${ }^{2}$ This framework is useful in that it will permit heterogeneous participation in the asset market. For example, an agent who possesses an endowment of the homogeneous consumption good in the first period of his or her life may choose to exchange part of his or her endowment for a title to an asset which may yield a dividend the following period. Also, agents in the last period of their life are faced with a trivial decision problem: They will sell all securities in order to maximize utility. That is, these agents will supply their securities inelastically. Therefore, two facts should be noted about the environment. First, in any period there will be one group of individuals who are net purchasers of assets, while there will be others who are net sellers of assets: not all agents participate in the asset market in the same way. Second, individuals in the second period of their life will supply all securities inelastically regardless of what forecasts of future dividends may be. This will be very important because equations such as (1) fail to have any relevance for the problem faced by any of these latter agents. We also think it of interest to inquire as to whether this heterogeneous participation in the asset market will enable us to produce high asset price variability in the absence of high risk aversion on the part of consumers. The overlapping generations construct seems even more appropriate when one considers that titles 
to durable capital goods usually last beyond the lifetime of any single agent. Therefore, the decision regarding the acquisition or sale of assets, or the production of new capital may best be answered within a framework of finite lived agents.

We are also interested in developing a model in which new capital may be produced. Agents may then trade titles to existing capital as well as invest in the production of new capital. An essential feature of such a model would be that investment be irreversible (i.e., capital must be putty-clay). This will allow us to consider the fluctuations of the market price of capital relative to its replacement cost on the one hand, and to aggregate investment on the other.

The remainder of this paper is organized as follows. In Section II we specify the nature of an overlapping generations model in which agents trade the titles to productive capital goods. Each period there is born a generation of individuals who live for two periods. These agents are endowed with a positive amount of a homogeneous consumption good in the first period of their life, and have no endowment in the second period. In the first period of their life, agents may surrender a portion of their endowment in return for a title to ownership of some of the existing capital. This individual can then collect the dividend yielded by the capital in the second period of his or her life. In addition, there exists a technology for converting the consumption good into capital which then yields a dividend in the subsequent period. Thus, agents may purchase existing capital and, at the same time, invest in the production of new capital. It will then be shown that an equilibrium exists for such an economy.

In Section III we show, by way of example, that price variability may result from endowment shocks, changes in the cost of producing new capital, or changes in the size of successive generations which are participating in the asset market. The model has no trouble confronting the fact that asset prices appear to be quite variable whilst dividends and consumption exhibit little variability。 
In Section IV we show that the price of capital will, in general, fail to possess the Martingale property.

In Section $V$ we show that if it takes more than one period to produce new capital, then the price of existing capital may rise above the cost of producing new capital--even in the steady state equilibrium. That is, the cost of producing new capital is no longer an upper bound on the price of existing capital.

The conclusions are presented in Section VI.

\section{AN OVERIAPPING GENERATION MODEL WITH CAPITAL ACCUMUIATION}

In this section we consider an overlapping generations model in which, at each date $(t), N_{t}$ identical two-period lived agents are born. Each agent born in period $(t)$ is endowed with $w_{t}$ units of the homogeneous consumption good when young and none in the second period of their life. Members of generation ( $t$ ) maximize a separable utility function $U\left(c_{1}^{t}\right)+V\left(c_{2}^{t}\right)$, which represents the utility derived from consumption in the first and second period of the agent's lifetime. Henceforth, we shall assume that $U(\cdot)$ and $V(\cdot)$ are strictly concave, twice continuously differentiable and strictly increasing. Further, we assume

$$
\begin{aligned}
& U^{\prime}\left(c_{1}^{t}\right) \rightarrow \infty \text { as } c_{1}^{t} \rightarrow 0 \\
& V^{\prime}\left(c_{2}^{t}\right) \rightarrow \infty \text { as } c_{2}^{t} \rightarrow 0 \\
& 0 \leqq 1+\frac{c_{2}^{t} v^{\prime \prime}\left(c_{2}^{t}\right)}{V^{\prime}\left(c_{2}^{t}\right)} \leqq \alpha<1 \\
& 0 \leqq 1+\frac{c_{1}^{t} U^{\prime \prime}\left(c_{1}^{t}\right)}{U^{\prime}\left(c_{1}^{t}\right)}
\end{aligned}
$$

It should be noted that equations (3) and (4) impose a restriction on relative risk aversion.

At the beginning of period ( $t$ ) the members of generation $(t-1)$, in aggregate, hold $\mathrm{K}_{\mathrm{t}}$ units of the available capital. All capital-is assumed to be putty-clay. 
That is, the capital good cannot be converted into the consumption good. However, agents alive at time $(t)$ can convert the consumption good into capital at the rate $\theta_{t}$. Therefore, at time $(t)$ an agent may convert $\theta_{t}$ units of the consumption good into one unit of capital. Capital also depreciates at the rate $(\delta)$ per period where $0<\delta<1$. A unit of capital produced prior to period ( $t$ ) will yield a dividend or rental of $r_{t}$ in period $(t)$.

Members of generation $(t)$ can, with their endowment, consume, purchase existing capital from the members of generation (t-1), or construct new capital of their own. Such an individual will purchases $\left(\mathrm{K}_{\mathrm{t}} / \mathrm{N}_{\mathrm{t}}\right)$ units of capital, per capita, from the members of generation $(t-1)$ at a price $P_{t}$ per unit. They also devote $\theta_{t} x_{t}$ units of the consumption good to producing new capital in the amount $x_{t}$. At time $(t+1)$, members of generation $(t)$ receive an exogenous rental, in units of the consumption good, of $r_{t+1}$ per unit of capital held at the beginning of period $(t+1)$. These agents then sell all their undepreciated capital holdings to members of generation $(t+1)$ at the price $P_{t+1}$ per unit.

The problem posed to the member of generation $(t)$ is to maximize $U\left(c_{1}^{t}\right)+V\left(c_{2}^{t}\right)$ subject to the constraints

$$
\begin{aligned}
& c_{1}^{t} \leq w_{t}-P_{t}\left(\frac{K_{t}}{N_{t}}\right)-\theta_{t} x_{t} \\
& c_{2}^{t} \leq P_{t+1}\left(\left(\frac{K_{t}}{N_{t}}\right)+x_{t}\right)(1-\delta)+\left(\frac{K_{t}}{N_{t}}+x_{t}\right) r_{t+1}
\end{aligned}
$$

where $P_{t+1}$ and $r_{t+1}$ are unknown at time $(t)$.

Equations (5) and (6) will hold with equality in any equilibrium. The aggregate capital stock in period $(t+1)$ is defined to be

$$
\mathrm{K}_{\mathrm{t}+1}=(1-\delta)\left(\mathrm{K}_{\mathrm{t}}+\mathrm{N}_{\mathrm{t}} \mathrm{x}_{\mathrm{t}}\right)
$$

Because capital production is irreversible we constrain $x_{t} \geq 0$.

The notation is as follows: 
$K_{t}=$ aggregate capital stock sold from members of generation $(t-1)$ to members of generation $(t)$.

$x_{t}=$ units of capital produced by a member of generation ( $t$ ) for use in period $(t+1)$

$\theta_{t}=$ the quantity of the consumption good needed to produce a unit of the capital good during period $(t)$.

$c_{1}^{t}=$ first period consumption by a member of generation ( $\left.t\right)$

$c_{2}^{t}=$ second period consumption by a member of generation $(t)$.

$P_{t}=$ price of a unit of capital in period $(t)$.

$r_{t}=$ rental received, per unit of capital by the agent who held capital at the beginning of period $(t)$. This rental will be received by the members of generation ( $t-1)$.

$N_{t}=$ number of agents born at time $(t)$.

$E_{t}(\cdot)=$ the expectation operator conditional on information available at date $(t)$

We assume that the realization of $\left(w_{t}, N_{t}, \theta_{t}, r_{t}\right)$ occurs prior to, or simultaneously with, the appearance of the young of generation $(t) 0^{3}$ We also assume that the vector $\left(w_{t}, N_{t}, \theta_{t}, r_{t}\right)$ is intertemporally i.i.d. with the joint cumulative distribution function $\Gamma(w, N, \theta, r)$ over the interval $[\underline{w}, \bar{w}] \times[\underline{N}, \bar{N}] \times[\underline{\theta}, \bar{\theta}] \times[\underline{r}, \bar{r}]$. Further, we assume

$$
\begin{aligned}
& 0<\underline{\underline{w}} \leq \bar{w}<\infty, \\
& 0<\underline{\underline{N}} \leq \overline{\mathrm{N}}<\infty, \\
& 0<\underline{\theta} \leq \bar{\theta}<\infty, \\
& 0<\underline{\underline{n}} \leq \bar{r}<\infty .
\end{aligned}
$$

If we define $k_{t}=\left(\mathrm{K}_{t} / \mathrm{N}_{\mathrm{t}}\right)$ as the per capita purchases of capital by members of generation ( $t$ ) from generation ( $t-1)$, then the agent's optimization problem can be rewritten as :

$$
\begin{aligned}
& \underset{k_{t}, x_{t}}{\operatorname{maximize}} U\left(c_{1}^{t}\right)+V\left(c_{2}^{t}\right) \text { subject to } \\
& c_{1}^{t}=w_{t}-P_{t} k_{t}-\theta_{t} x_{t} \\
& c_{2}^{t}=\left(P_{t+1}(1-\delta)+r_{t+1}\right)\left(k_{t}+x_{t}\right) .
\end{aligned}
$$


The first order necessary conditions for the above optimization problem are:

$$
\begin{aligned}
& P_{t} U^{\prime}\left(c_{1}^{t}\right)=E_{t}\left[V^{\prime}\left(c_{2}^{t}\right)\left(P_{t+1}(1-\delta)+r_{t+1}\right)\right] \\
& \theta_{t} U^{\prime}\left(c_{1}^{t}\right) \geq E_{t}\left[V^{\prime}\left(c_{2}^{t}\right)\left(P_{t+1}(1-\delta)+r_{t+1}\right)\right] .
\end{aligned}
$$

Equation (11) will hold with equality if $x_{t}>0$. Equations (10) and (11) together imply that

$$
\left.\begin{array}{l}
x_{t}>0 \Rightarrow P_{t}=\theta_{t} \\
P_{t}<\theta_{t} \Rightarrow x_{t}=0
\end{array}\right\}
$$

This says that the price of existing capital will never rise above the cost of production of new capital, and it may fall below the latter if there is no investment in new capital.

The market clearing condition is that $k_{t}=\left(\mathrm{K}_{\mathrm{t}} / \mathrm{N}_{\mathrm{t}}\right)$. Equation (7) also implies that $N_{t+1} k_{t+1}=(1-\delta)\left(k_{t}+N_{t} x_{t}\right)$, or that

$$
k_{t+1}=\frac{(1-\delta)}{N_{t+1}}\left(k_{t}+N_{t} x_{t}\right)
$$

The "state" of the economy at time $(t)$ is defined to be the vector of variables $\left(w_{t}, N_{t}, \theta_{t}, r_{t}, k_{t}\right)$. We shall be seeking a stationary equilibrium for the economy. That is, we shall study equilibria in which the price of capital and the optimal investment function can be written as functions of a subset of this state vector. Such an equilibrium can be said to be stationary because agents who are members of different generations, but who are faced with the same values for the state variables, are then faced with the same optimization problem.

The individual agent then believes that the capital stock evolves according to:

$$
\left.\mathrm{K}_{t+1}=\tilde{\mathrm{h}}_{\left(\mathrm{w}_{t}\right.}, \mathrm{N}_{t}, \theta_{t}, \mathrm{~K}_{\mathrm{t}}\right) \text {, }
$$

which implies that individual investment in new capital is described by the equation

$$
x_{t}=\tilde{x}_{t}\left(w_{t}, N_{t}, \theta_{t}, K_{t}\right)=\left(\frac{1}{N_{t}}\right)\left(\frac{\tilde{h}\left(w_{t}, N_{t}, \theta_{t}, K_{t}\right)}{(1-\delta)}-k_{t}\right) .
$$

The individual further believes that the price of capital at $(t), P_{t}$, is related to the state as follows: 


$$
P_{t}=\tilde{q}\left(w_{t}, N_{t}, \theta_{t}, K_{t}\right)
$$

and the vector of random variables $\left(w_{t}, N_{t}, \theta_{t}, r_{t}\right)$ is intemporally i.i.d. with the joint cumulative distribution function $\widetilde{\Gamma}(w, N, \theta, r)$ over the interval

$[\underline{w}, \bar{w}] \times[\underline{N}, \bar{N}] \times[\underline{\theta}, \bar{\theta}] \times[\underline{r}, \bar{r}]$.

A few words should be said concerning the role of $r_{t}$ as a state variable. Members of generation $(t)$ are not affected by the realization of $r_{t}$ because the rental goes to members of generation $(t-1)$. Agents of generation $(t)$ are, however, affected by the realization of $r_{t+1}$. But $r_{t+1}$ is unknown at time $(t)$. Since the vector $\left(w_{t}, N_{t}, \theta_{t}, x_{t}\right)$ is distributed $i . i . d$., we know that the realization of $r_{t}$ provides no useful information to members of generation ( $t)$. Hence, although the realization of $r_{t}$ is a characteristic of the state at time $(t)$, its realization will not affect the decision problem of members of generation ( $t$ ). Therefore, equations (14), (15) and (16) are written with $r_{t}$ deleted.

Now we assume that agents have expectations which are consistent with their environment in that:

(1) the actual evolution of capital stock is that given by equation (14);

(2) the price of capital will actually follow the law of motion given by equation (16); and

(3) the perceived cumulative distribution function $\widetilde{\Gamma}(w, N, \theta, r)$ is the same as the actual cumulative distribution function $\Gamma(w, N, \theta, r)$.

In Appendix A we present a proof of the existence of a stationary solution to the system described by equations (8) through (13)。 In Appendix B we show sufficient conditions for this equilibrium to be unique. The latter appendix also contains a general comment regarding the uniqueness of such equilibria.

Several characteristics should now be noted concerning the pricing function. The price of capital at time $(t)$ has an upper bound of $\theta_{t}$ and may fall below $\theta_{t}$ only if no new capital is produced. The variability of $P_{t}$ will depend upon the structure of the environment. However, we can see from equation (16) that the realization of $r_{t}$ has no effect upon the equilibrium price of capital. The reason for this is obvious. 
The realization of $r_{t}$ does not affect the decisions made by members of generation $(t)$, and since the vector $\left(w_{t}, N_{t}, \theta_{t}, r_{t}\right)$ is intertemporally independent, the realization of $r_{t}$ will provide no useful information concerning the environment which members of generation ( $t$ ) will face in the second period of their life. However, we need not restrict ourselves to environments in which the vector $\left(w_{t}, N_{t}, \theta_{t}, r_{t}\right)$ is intertemporally independent. ${ }^{4}$ By removing this restriction, the state vector could be enlarged to include present and past realizations of these exogenous variables. Then equation (16) would be a function of all these variables. Further, it may be that $r_{t}$ would become an argument in equation (16) and hence the realization of $r_{t}$ could affect $P_{t}$. For example, if the $r_{t}$ process is correlated in some manner, then the realization of $r_{t}$ would help to predict $r_{t+1^{\circ}}$ In this case, the realization of $r_{t}$ alone may influence $P_{t^{\circ}}$ However, the occurrence of an $r_{t}$ which implies that future rentals should be higher does not mean that the price of capital should also rise. To illustrate this, consider the case developed in Appendix A where equation (16) is non-decreasing in $w_{t}$ and $\theta_{t}$. Further assume that

$$
\begin{aligned}
& \text { Covariance }\left(w_{t+1}, r_{t}\right)<0, \\
& \text { Covariance }\left(\theta_{t+1}, r_{t}\right)<0, \text { and } \\
& \text { Covariance }\left(r_{t+1}, r_{t}\right)>0 .
\end{aligned}
$$

Should there occur, in any period, an unusually low realization of $r_{t}$, this could cause future rentals to be lower at the same time as causing future endowments and costs of production of capital to rise. Thus, if the latter effects dominated the former, we could have that the price of capital, and the dividends yielded by the capital, would be negatively correlated: We think that this type of result would be difficult to motivate using a relationship of the type shown in equation (1). of course, in general, the observed correlations would depend upon the probability structure of the environment.

Lastly, we are reminded that this framework is not unrelated to the literature on "Tobin's q" (see Sargent [24] and Tobin [30]). In this case 


$$
q=\frac{\text { price of existing capital }}{\cos t \text { of producing new capital }}=\frac{P_{t}}{\theta_{t}} \text {. }
$$

Then we have:

$$
\begin{gathered}
x_{t}>0 \Rightarrow q=1 \\
q<1 \Rightarrow x_{t}=0
\end{gathered}
$$

Therefore, this statement implies that the model is consistent with the literature that has found a positive association between the level of investment and a shadow price of capital obtained from stock market data (see, for example, [19]).

\section{SAMPIE ECONOMIES}

In this section we study a particular environment of the type described in the previous section. We assume that a11 agents have preferences of the form

$$
U\left(c_{1}^{t}\right)+v\left(c_{2}^{t}\right)=\ln \left(c_{1}^{t}\right)+\ln \left(c_{2}^{t}\right) \text { 。 }
$$

Equations (10) and (11) become

$$
\begin{aligned}
& {\left[\frac{P_{t}}{w_{t}-P_{t} k_{t}-\theta_{t} x_{t}}\right]=E_{t}\left[\frac{1}{k_{t}+x_{t}}\right]} \\
& {\left[\frac{\theta_{t}}{w_{t}-P_{t} k_{t}-\theta_{t} x_{t}}\right] \geqq E_{t}\left[\frac{1}{k_{t}+x_{t}}\right] .}
\end{aligned}
$$

Because of (8) we have

$$
E_{t}\left[\frac{1}{k_{t}+x_{t}}\right]=\left[\frac{1}{k_{t}+x_{t}}\right] \text {. }
$$

If $x_{t}>0$, then $P_{t}=\theta_{t}$ so that we have

$$
\theta_{t}\left(k_{t}+x_{t}\right)=\left(\frac{{ }^{w}}{2}\right)
$$

and so

$$
k_{t+1}=N_{t}\left(k_{t}+x_{t}\right)(1-\delta)=\left(\frac{N_{t} w_{t}}{2 \theta_{t}}\right)(1-\delta) .
$$

We then have

$$
x_{t}=\frac{1}{N_{t}}\left[\frac{k_{t+1}}{(1-\delta)}-k_{t}\right] \text { or }
$$




$$
x_{t}=\left[\frac{w_{t}}{2 \theta_{t}}-\frac{K_{t}}{N_{t}}\right] .
$$

If $P_{t}<\theta_{t}$, we have $x_{t}=0$ and we have

and so we know

$$
P_{t}\left(\frac{K_{t}}{N_{t}}\right)=\left(\frac{w_{t}}{2}\right),
$$

$$
P_{t}=\left(\frac{{ }^{W}}{2}\right)\left(\frac{N_{t}}{K_{t}}\right) .
$$

and, hence, in this case we have

$$
\mathrm{K}_{\mathrm{t}+1}=(1-\delta) \mathrm{K}_{\mathrm{t}}
$$

For this example the functional forms (14), (15) and (16), respectively,

take the forms

$$
\begin{aligned}
\mathrm{K}_{t+1} & =\max \left\{\left(\frac{\mathrm{N}^{\mathrm{w}} \mathrm{t}}{2 \theta_{t}}\right)(1-\delta),(1-\delta) \mathrm{K}_{\mathrm{t}}\right\} \\
\mathrm{x}_{\mathrm{t}} & =\max \left\{0,\left(\frac{\mathrm{w}_{\mathrm{t}}}{2 \theta_{t}}-\frac{\mathrm{K}_{\mathrm{t}}}{\mathrm{N}_{\mathrm{t}}}\right)\right\} \\
\mathrm{P}_{\mathrm{t}} & =\min \left\{\theta_{t},\left(\frac{\mathrm{w}_{t} \mathrm{~N}_{t}}{2 \mathrm{~K}_{t}}\right)\right\} .
\end{aligned}
$$

Equation (17) reveals that the upper bound on capital stock is

$$
\overline{\mathrm{K}}=\left(\frac{\overline{\mathrm{N}} \overline{\mathrm{W}}}{2 \underline{\theta}}\right)(1-\delta)
$$

and the lower bound on capital stock is

$$
\underline{\mathrm{K}}=\left(\frac{\underline{\mathrm{N}} \underline{\underline{w}}}{2 \bar{\theta}}\right)(1-\delta) \text {. }
$$

Two special cases must then be considered. These are illustrated in Figures 1 and 2. In Figure 1 we see a case where there is investment in capital $\left(x_{t}>0\right)$ every period and therefore $P_{t}=\theta_{t} \forall t$. In this case, capital depreciates at such a high rate that agents find it optimal to produce more capital every period. This situation will occur if

$$
\left.(1-\delta)<\frac{\underline{N} \underline{\underline{w}} \underline{\underline{\theta}}}{\frac{\mathrm{N}}{\bar{\theta}}}\right) .
$$




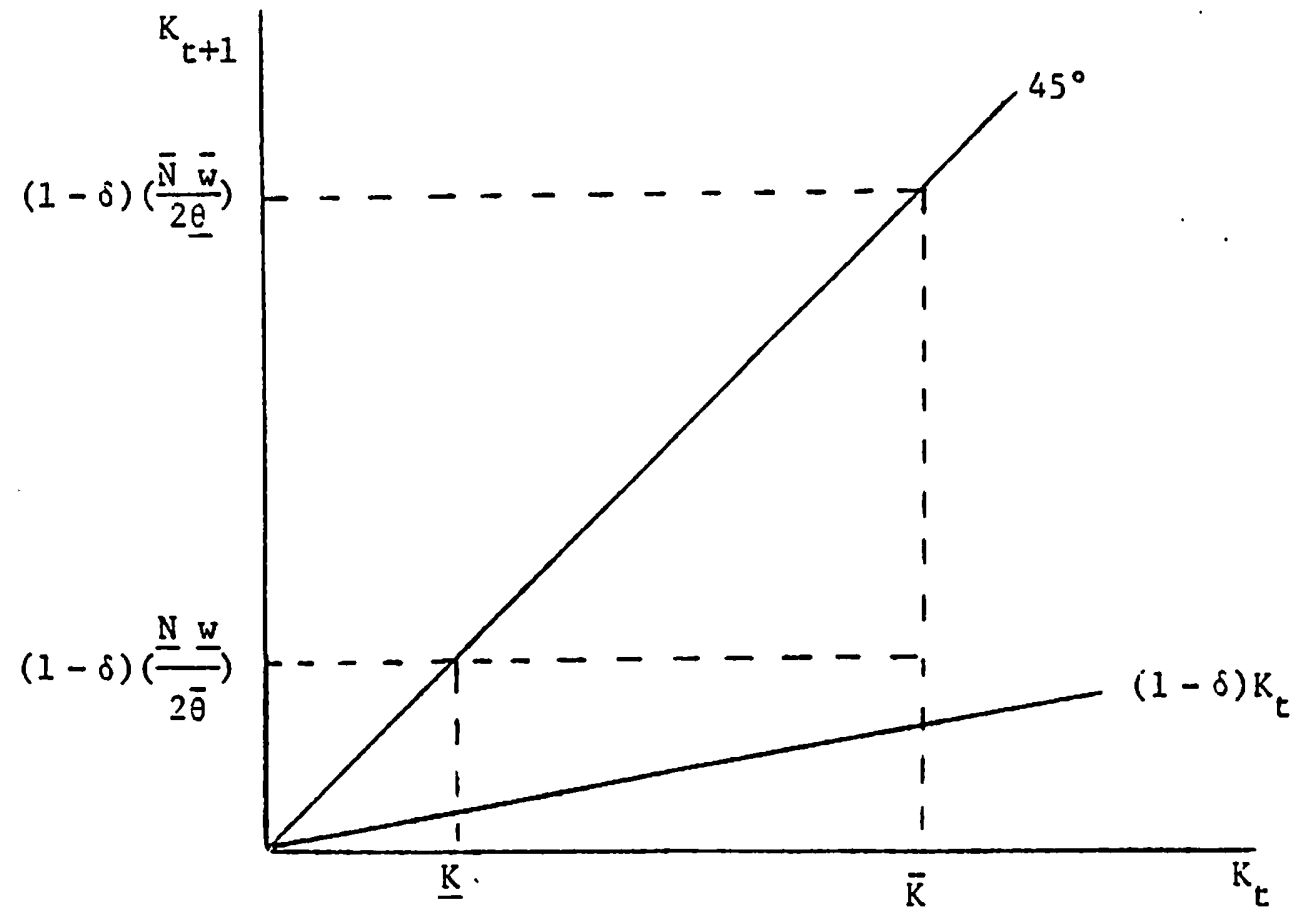

Figure 1

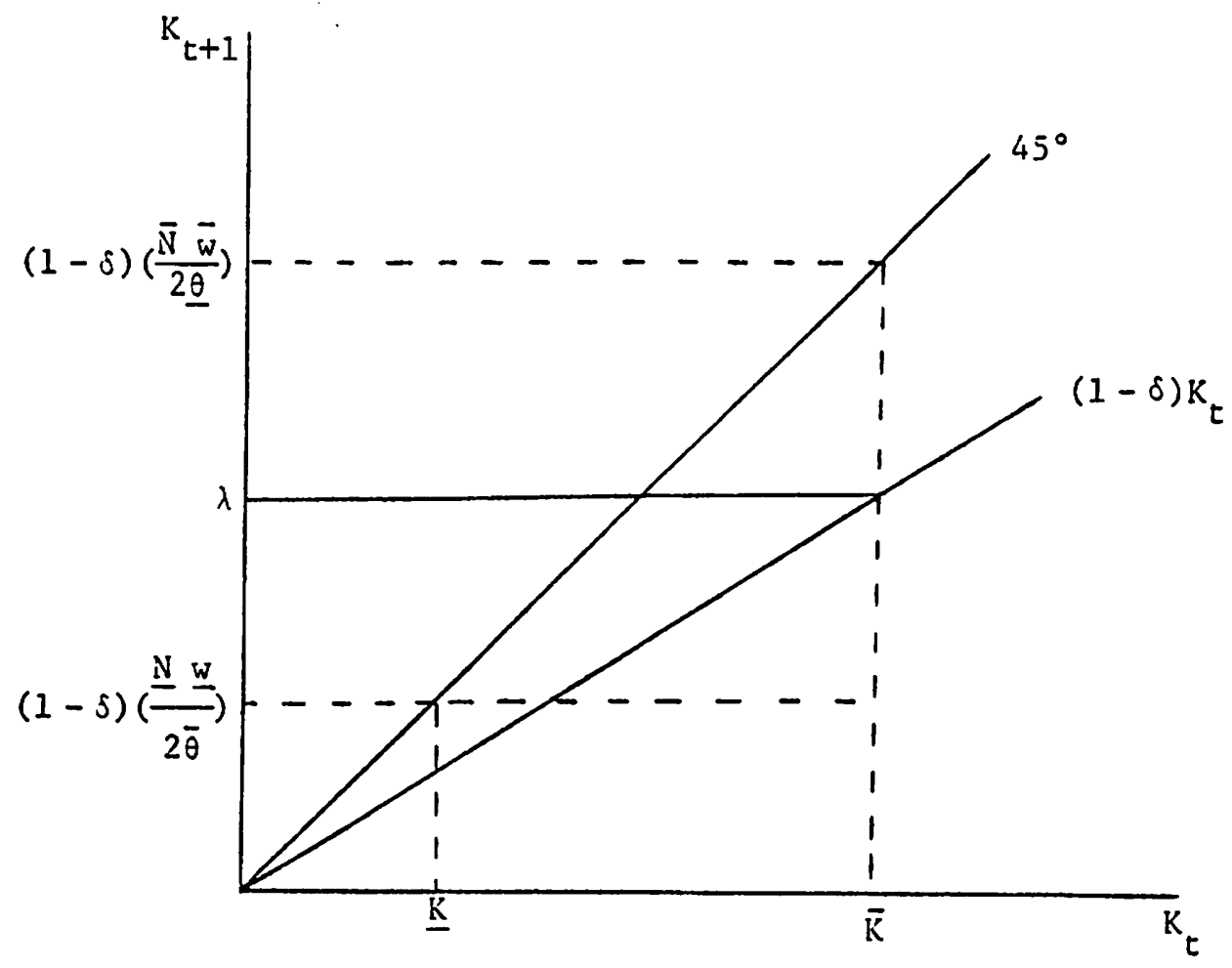

Figure 2. 
Figure 2 illustrates the case where there may or may not be investment in new capital in any given period. If

$$
K_{t}>\left(\frac{t_{t}^{w} t}{2 \theta_{t}}\right)
$$

then

$$
\begin{aligned}
& x_{t}=0 \text { and } \\
& P_{t}=\left(\frac{{ }_{t} N_{t}}{2 K_{t}}\right) .
\end{aligned}
$$

Conversely, if

$$
k_{t}<\left(\frac{N_{t} t_{t}}{2 \theta_{t}}\right)
$$

then

$$
\begin{aligned}
& x_{t}=\left(\frac{w_{t}}{2 \theta_{t}}-\frac{K_{t}}{N_{t}}\right) \text { and } \\
& P_{t}=\theta_{t}
\end{aligned}
$$

For the particular case shown in Figure 2, whenever

$$
(1-\delta)\left(\frac{t^{W} t}{2 \theta_{t}^{W}}\right)>\lambda
$$

we then have $x_{t}>0$ and $P_{t}=\theta_{t}$ with probability one.

The reduced forms (17)-(19) allow us to study how the price of capital, as well as aggregate variables, behave within a stochastic environment. Table 1 contains an example of an economy in which uncertainty is introduced through endowment shocks. For different depreciation rates we have calculated the average price of capital as well as standard deviation of the price of capital. We also show relative volatility measures of the price of capital, aggregate consumption, investment and total income. Table 2 contains similar statistics for an environment in which there are shocks to the cost of production of capital. Lastly, Table 3 contains an example of an economy in which there is uncertainty concerning the size of future generations. In all cases we can see that the price of capital will have a positive variance while the returns or dividends to the capital are constant. 


$$
\begin{gathered}
\text { Table } 1^{\dagger} \\
N=1, \theta=0.5, r=2.0
\end{gathered}
$$

Probability Distribution of $\mathrm{w}$

$\begin{array}{rc}\frac{w}{5} & \text { Probability } \\ 10 & 1 / 2 \\ 1 / 2\end{array}$

$\begin{array}{lllllll}\frac{\delta}{.02} & \frac{\overline{\mathrm{P}}}{.3854} & \frac{\sigma(\mathrm{P})}{.1198} & \frac{\rho(\mathrm{P})}{.31095} & \frac{\rho(\mathrm{c})}{.0948} & \frac{\rho(\mathrm{x})}{1.529} & \frac{\rho(\mathrm{y})}{.0988} \\ .05 & .3936 & .1121 & .2848 & .1051 & 1.341 & .1110 \\ .10 & .4094 & .1001 & .2456 & .1373 & 1.257 & .1378 \\ .25 & .4536 & .06965 & .1535 & .2242 & .9974 & .1967\end{array}$

Definition of Symbols

$\overline{\mathrm{P}}=$ average price of capital.

$\sigma(P)=$ standard deviation of the price of capital.

$\rho(P)=$ coefficient of variation of the price of capital.

$\rho(c)=$ coefficient of variation of consumption.

$\rho(x)=$ coefficient of variation of investment.

$\rho(y)=$ coefficient of variation of total net income.

The coefficient of variation is defined to be the standard

deviation divided by the mean.

'In the examples shown in Tables 1 through 5 the specified probability distribution was used to generate values for the exogenous variables for each time period. This would then result in numerical values for the asset price as well as aggregate consumption, investment, and income for each period. We then used a sample size of 8000 to calculate the relevant statistics mentioned in these tables. 
Table 2

$$
\mathrm{N}=1, \mathrm{w}=10.0, \mathrm{r}=2.0
$$

Probability Distribution of $\theta$

$\begin{array}{cc}\frac{\theta}{2.0} & \text { Probability } \\ 0.5 & 1 / 2 \\ 1 / 2\end{array}$

$\begin{array}{lllllll}\frac{\delta}{.02} & \frac{\overline{\mathrm{P}}}{.51156} & \frac{\sigma(\mathrm{P})}{.01747} & \frac{\rho(\mathrm{P})}{.03416} & \frac{\rho(\mathrm{c})}{.0275} & \frac{\rho(\mathrm{x})}{1.487} & \frac{\rho(\mathrm{y})}{.0211} \\ .05 & .53109 & .04978 & .0937 & .0639 & 1.409 & .0485 \\ .10 & .57099 & .12517 & .2192 & .1189 & 1.3411 & .0877 \\ .25 & .7346 & .3676 & .5004 & .2489 & 1.1888 & .01641\end{array}$

Table 3

$$
w=10.0, \theta=0.5, r=2.0
$$

Probability Distribution of $\mathrm{N}$

$\begin{array}{rc}\frac{N}{100} & \text { Probability } \\ 70 & 1 / 2 \\ 1 / 2\end{array}$

$\begin{array}{lllllll}\frac{\delta}{.02} & \frac{\overline{\mathrm{P}}}{.4342} & \frac{\sigma(\mathrm{P})}{.06807} & \frac{\rho(\mathrm{P})}{.1568} & \frac{\rho(\mathrm{c})}{.05598} & \frac{\rho(\mathrm{x})}{1.533} & \frac{\rho(\mathrm{y})}{.0316} \\ .05 & .4458 & .05908 & .1325 & .0728 & 1.3369 & .0672 \\ .10 & .4637 & .04747 & .10237 & .10376 & 1.1329 & .1099 \\ .25 & .4919 & .01429 & .0291 & .15589 & .6882 & .1594\end{array}$


Before we can compare statistics derived from such a model with documented statistics or stylized facts, we must decide on the length of the "period" of our model. Only after this decision is made can we determine that we should compare the model to data which are monthly, quarterly or yearly. However, the model does not lend itself to an easy answer to such a question. This problem is not something which this model alone must face. Even if agents were infinitely lived, there would still be a problem in how to "match the model with the data". With this caveat in mind we can, at least casually, compare these examples to statistics in the literature on this topic. Shiller [26] found coefficients of variation on stock prices, for two different set of annual data, of 0.344 and 0.362 . Grossman and Shiller [5] found that some degree of this variability could be explained by using data on consumption of nondurables and services. We have found the coefficient of variation for consumption of nondurable goods plus services to be $(0.0464)^{5}$ from 1929 to 1979 and that for consumption of goods and services from 1889 to 1953 to be $(0.0592) .^{6}$ The first row of Table 1 is close to mimicking these statistics. The use of lower depreciation rates would yield higher price volatility with lower consumption variability when there are endowment shocks. In any case, these examples are capable of yielding price variability which is greater than aggregate consumption variability even when the rental paid to owners of capital is constant. These examples are also consistent with the observation that investment is more volatile than either aggregate income or consumption.

of course, in these environments the price variability is induced by factors other than changes in returns to capital. Table 4 presents an example of an economy in which there exists variability in rentals but no variability in the price of capital or investment.

Hall [6] has found that changes in stock prices in a given period help predict aggregate consumption in the following period. ${ }^{7}$ Table 5 presents an example of an economy in which this phenomenon exists. Here aggrègate consumption is regressed on 


\section{Table 4}

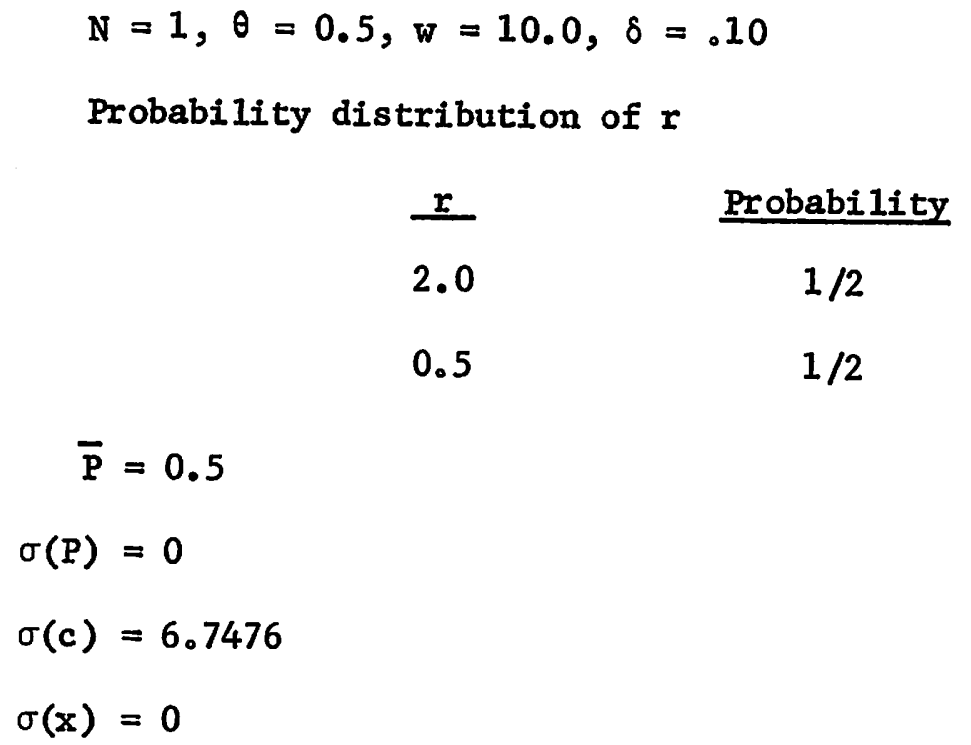

\section{Table 5}

$\mathrm{N}=1, \theta=0.5, \mathrm{r}=2.0, \delta=.10$

Probability distribution of $w$

$$
\begin{aligned}
& \text { w Probability } \\
& 10 \quad 1 / 2 \\
& 5 \quad 1 / 2 \\
& \begin{aligned}
c_{t}=9.166+ & \underset{(.0176)}{0.6019} \cdot c_{t-1}+\underset{(.3818)}{4} \\
(.686) & \Delta P_{t-1}
\end{aligned} \\
& R^{2}=.3881 \\
& \Delta P_{t-1}=P_{t-1}-P_{t-2}
\end{aligned}
$$

Numbers in parentheses are standard errors. 
lagged consumption and the lagged change in the price of capital. Coefficients on both independent variables are significant at the 95 percent confidence level. We feel the reason for this result is enlightening. It lies in the fact that aggregate consumption has two sources : endowments and capital returns. A higher price of capital in a period may signal increased investment in capital, and therefore higher total rentals in the future. This result could not be obtained from the model used by Lucas [18]. In the latter framework knowledge of aggregate consumption reveals all there is to know about the economy since the only source of the consumption good is the rental yielded by the capital. The price of the relevant asset gives no extra information with regard to future consumption.

IV. THE MARTINGALE PROPERTY

From equation (10) we have

$$
P_{t}=\frac{E_{t}\left[V^{\prime}\left(c_{2}^{t}\right)\left(P_{t+1}(1-\delta)+r_{t+1}\right)\right]}{U^{\prime}\left(c_{1}^{t}\right)} .
$$

The price of capital, adjusted for depreciation and the rental payment, will in general not follow a martingale for reasons similar to that given by Lucas [18]: $U(\cdot)$ and $V(\cdot)$ are not generally constant functions of consumption.

It is also of interest to consider the situation illustrated in Figure 1. In this environment, where there is investment in every period, we have that $P_{t}=\theta_{t}$ for all $(t)$. If the $\left\{\theta_{t}\right\}$ process closely resembles a martingale, then the $\left\{P_{t}\right\}$ process will also resemble a martingale. However, as noted by LeRoy [14], this is not what is generally meant when we speak of the martingale property. Instead, it is the stock price plus dividends which should follow a martingale. In any case, as emphasized by Danthine [3], Lucas [18] and Sargent [23], the failure of $P_{t}$ to follow a martingale does not imply that markets are not in equilibrium. 
V. AN EXAMPLE IN WHICH CAPITAL TAKES TIME TO PRODUCE

In Section III we showed that several factors could cause the price of an asset to exhibit variability. However, because capital could be "produced today for use tomorrow", it followed that the price of existing capital could not rise above the cost of producing new capital. Thus, because this cost of producing new capital acts as an upper bound on the price of existing capital, it may actually restrict the price of existing capital from exhibiting even more variability. In this section we present an example of such an economy where there is no such bound on the price of capital in equilibrium. Because the bound is no longer present, it may then be that the price of existing capital can possess even more variability in such a stochastic environment.

In this section we consider an overlapping generation model in which at each date $(t), N(>0)$ identical two-period lived agents are born. Each agent born in period $(t)$ is endowed with $w_{t}$ units of the homogeneous consumption good when young and none in the second period of their life. Each agent maximizes a separable utility function of the type described in Section II.

At the beginning of period $(t)$, members of generation $(t-1)$ hold in aggregate $\mathrm{K}_{\mathrm{t}}$ units of the available productive capital. The capital may not be converted into the consumption good but agents alive at time $(t)$ can convert the consumption good into capital at the rate $\theta$. However if $\theta$ units of the consumption good are set aside in period ( $t$ ) for the production of capital, the capital will not be "productive" until the beginning of period $(t+n)$. In period $(t)$, productive capital yields a dividend or rental of $\left(r_{t}\right)$ per unit per period. Further, productive capital depreciates at the rate $(\delta)$ per period where $0<\delta<1$.

Members of generation $(t)$ can, with their endowment, consume, purchase existing productive capital from members of generation $(t-1)$, devote some of their consumption good to the production of new capital, or purchase ownership to units 
of the consumption good which were devoted to capital production in the past but which are not yet productive. We assume that it takes $n$ periods for any capital to become productive. Thus, agents of generation ( $t$ ) who devote $\left(\theta \mathrm{x}_{t}\right)$ units of the consumption good to producing new capital, will have produced $x_{t}$ units of the consumption good which will be productive at the beginning of period $(t+n)$. The price, in period $(t)$, of productive capital will be denoted by $P_{t}$, whilst the price of the homogeneous consumption good devoted to capital production in period $(t-i)$, which will be productive in period $(t-i+n)$ will be denoted by $\mathrm{q}_{t}^{i}$.

A feature of interest of this environment is that in period $(t)$, members of generation ( $t-1)$ will supply all stocks, of productive and soon-to-be-productive capital, inelastically.

The problem posed to the members of generation $(t)$ is to maximize $U\left(c_{1}^{t}\right)+V\left(c_{2}^{t}\right)$ subject to the constraints

$$
\begin{aligned}
& c_{1}^{t} \leqq w_{t}-P_{t}\left(k_{t}+x_{t-n+1}\right)-\sum_{i=2}^{n-1} q_{t}^{i} x_{t-n+i}-\theta x_{t} \\
& c_{2}^{t} \leqq\left(P_{t+1}(1-\delta)+r_{t+1}\right)\left(k_{t}+x_{t-n+1}\right)+\sum_{i=2}^{n-1} q_{t+1}^{i} x_{t-n+i+1}+P_{t+1} x_{t-n+2}
\end{aligned}
$$

of course, the terms in the summation will be zero if $n=2$. Section II contains the case where $n=1$. We constrain $x_{j} \geq 0$ for all $j$. The market clearing conditions are then

$$
\begin{aligned}
& k_{t}=k_{t} / N \\
& k_{t+1}=\left(k_{t}+x_{t-n+1}\right)(1-\delta)
\end{aligned}
$$

The first order conditions for the agent's optimization problem are then

$$
\left.P_{t} U^{\prime}\left(c_{1}^{t}\right)=E_{t}\left\{p_{t+1}(1-\delta)+r_{t+1}\right) V^{\prime}\left(c_{2}^{t}\right)\right\}
$$$$
q_{t}^{2} u^{\prime}\left(c_{1}^{t}\right) \geqq E_{t}\left\{\left(P_{t+1} v^{\prime}\left(c_{2}^{t}\right)\right\} \quad \text { (with equality if } x_{t-n+2}>0\right. \text { ) }
$$ 


$$
\begin{array}{ll}
\left.q_{t}^{i} u^{\prime}\left(c_{1}^{t}\right) \geqq E_{t}\left\{q_{t+i}^{i-1} v^{\prime}\left(c_{2}^{t}\right)\right\} \quad \text { (with equality if } x_{t-n+1}>0 \text { for } i=3,4, \ldots, n-1\right) \\
\left.\theta u^{\prime}\left(c_{1}^{t}\right) \geqq E_{t}\left\{q_{t+1}^{n-1} v^{\prime}\left(c_{2}^{t}\right)\right\} \quad \text { (with equality if } x_{t}>0\right) .
\end{array}
$$

Our goal is to provide an example of an economy where the price of capital will rise above its cost of production. We provide an example where we use the utility function $U\left(c_{1}^{t}\right)+V\left(c_{2}^{t}\right)=\ln \left(c_{1}^{t}\right)+\ln \left(c_{2}^{t}\right)$ and specify the following parameters

$$
\begin{aligned}
& w_{t}=10 \quad \forall t \\
& r_{t}=5 \quad \forall t \\
& \delta=\theta=1 / 2
\end{aligned}
$$

We set $n=2$, so that consumption good which is set aside for capital production in period $(t)$ would be productive in period $(t+2)$. In this economy, the steady state equilibrium will have

$$
\begin{array}{rlrl}
P_{t} & =P_{t+1} & & \forall t \\
k_{t} & =k_{t+1} & & V t \\
\delta k_{t} & =x_{t} & V t
\end{array}
$$

The steady state value for the individual holdings of capital stock will be $k=1.9237$ while the equilibrium price of capital will be $P=1.89948$. Thus the equilibrium price of capital, in units of the consumption good, will be higher than the cost of production of capital.

Because the price of capital does not have an upper bound in such an environment, as opposed to the environment in section II, the price of capital may exhibit even more variability。

\section{CONCLUSION}

We have developed an equilibrium model in which the price of capital may exhibit variability which is not attributable to changes in rentals or dividends yielded by capital. In our environment, these factors could be endowment shocks, changes in the cost of producing new capital, or changes in the number of asset market participants. The method by which existing capital is priced does not imply any 
obvious correlation patterns between the price of capital and the rentals which it yields. In fact, the two variables could exhibit negative correlation. In a model in which it takes one period to produce new capital, the price of existing capital will equal the cost of production if new capital is being produced. However, if the price of existing capital is below the current cost of production, investment must be zero. The technological rigidity in this environment impedes rapid decreases in the capital stock and imposes an upper bound on the price of capital. We then showed that if capital takes more than one period to produce, this upper bound is removed. It remains to be seen as to whether this would permit the equilibrium price of existing capital to possess even greater volatility. 


\section{APPENDIX A}

This is a variation of a proof devised by Aiyagari [1].

We rewrite equations (8) through (13) as

$$
\begin{aligned}
& c_{1}^{t}=w_{t}-\frac{P_{t} K_{t+1}}{N_{t}(1-\delta)} \\
& c_{2}^{t}=\frac{P_{t+1} K_{t+1}}{N_{t}}+\frac{r_{t+1} K_{t+1}}{(1-\delta) N_{t}} \\
& {\left[\frac{P_{t} K_{t+1}}{(1-\delta) N_{t}}\right] U^{\prime}\left(c_{1}^{t}\right)=E_{t}\left[c_{2}^{t} V^{\prime}\left(c_{2}^{t}\right)\right]} \\
& K_{t+1}>(1-\delta) K_{t} \Rightarrow P_{t}=\theta_{t} \\
& P_{t}<\theta_{t} \Rightarrow K_{t+1}=(1-\delta) K_{t} .
\end{aligned}
$$

Now we seek functions $h\left(w_{t}, k_{t}, N_{t}, \theta_{t}\right)$ and $q\left(w_{t}, k_{t}, N_{t}, \theta_{t}\right)$ such that (Al) - (A4) hold identically in $\left(w_{t}, K_{t}, N_{t}, \theta_{t}\right)$ when we set

$$
\begin{aligned}
& k_{t+1}=h\left(w_{t}, k_{t}, N_{t}, \theta_{t}\right) \\
& P_{t}=q\left(w_{t}, k_{t}, N_{t}, \theta_{t}\right) .
\end{aligned}
$$

In the remainder of this appendix we seek to show that such functions exist.

Define the function $n(z, w)$ as the solution $n$ in the following equation:

$$
\eta U^{\prime}(w-\eta)=z \text { for } w, z \geqq 0 \text {. }
$$

Since $U(\cdot)$ is strictly concave, and $U^{\prime}\left(c_{1}^{t}\right) \rightarrow \infty$ as $c_{1}^{t}+0$, it is clear 
that for each $w, z \geqq 0$, there exists a unique $\eta \varepsilon[0, w]$ solving the above equation. Since $U(\cdot)$ is twice continuously differentiable, $n(\cdot, \cdot)$ is once differentiable, and its elasticities are given by:

$$
\frac{2 \eta_{1}}{\eta}=\frac{U^{\prime}(w-\eta)}{U^{\prime}(w-\eta)-\eta U^{\prime \prime}(w-\eta)} .
$$

Consequently we have

$$
0 \leqq \frac{2 \eta_{1}}{n} \leqq 1
$$

Also,

$$
\frac{w n_{2}}{\eta}=\frac{-w U^{\prime \prime}(w-\eta)}{U^{\prime}(w-n)-n U^{\prime \prime}(w-n)}
$$

and consequently

$$
0 \leqq \frac{w \eta_{2}}{n} \leqq 1
$$

by equation (4).

Henceforth we assume that there exists a $\underline{K}$ such that:

$$
\left.\eta\left(c_{2}^{t} V^{\prime}\left(c_{2}^{t}\right), \underline{w}\right)\right|_{c_{2}^{t}=\frac{\underline{r} \underline{K}}{\bar{N}}} \geqq \frac{\underline{K} \underline{\theta}}{(1-\delta) \bar{N}} .
$$

Now define

$$
\overline{\mathrm{K}}=\frac{(1-\delta)}{\delta}\left(\frac{\overline{\mathrm{N}} \overline{\mathrm{w}}}{\underline{\theta}}\right) .
$$

We will see that $\underline{K}$ and $\bar{K}$ will serve as upper and lower bounds, respectively, on the aggregate capital stock in the sense that if $\mathrm{K}_{\mathrm{t}} \varepsilon[\underline{\mathrm{K}}, \overline{\mathrm{K}}]$, we must have $\mathrm{K}_{\mathrm{t}+1} \in[\underline{\mathrm{K}}, \overline{\mathrm{K}}]$. We assume that the economy 
begins with $\mathrm{K}_{\mathrm{t}} \varepsilon[\underline{\mathrm{K}}, \overline{\mathrm{K}}]$. To show that $\overline{\mathrm{K}}$ is an upper bound for the aggregate capital stock, note that if $\mathrm{K}_{t} \leqq \mathrm{~K}_{\text {we have }}$

$$
\begin{aligned}
\mathrm{K}_{\mathrm{t}+1} & =(1-\delta)\left(\mathrm{K}_{\mathrm{t}}+\mathrm{N}_{\mathrm{t}} \mathrm{x}_{\mathrm{t}}\right) \leqq(1-\delta)\left(\overline{\mathrm{K}}+\frac{\overline{\mathrm{N}} \overline{\mathrm{w}}}{\underline{\theta}}\right) \\
& =\overline{\mathrm{K}}+\left[-\delta \overline{\mathrm{K}}+\frac{(1-\delta) \overline{\mathrm{N}} \overline{\mathrm{w}}}{\underline{\theta}}\right]=\overline{\mathrm{K}} .
\end{aligned}
$$

Let

$$
A\left(w_{t}, k_{t}, N_{t}\right):[\underline{w}, \bar{w}] \times[\underline{k}, \bar{k}] \times[\underline{N}, \bar{N}] \rightarrow\left[\frac{\underline{\theta} \underline{k}}{\bar{N}(1-\delta)}, \frac{\bar{\theta} \bar{k}}{\underline{N}(1-\delta)}\right]
$$

and let $\mathrm{A}(\cdot, \cdot, \cdot)$ be continuous in all arguments and non-decreasing in its first two arguments. Let

$$
\begin{aligned}
& k_{t+1}=[1-\delta] \max \left\{\frac{A\left(w_{t}, K_{t}, N_{t}\right)}{\theta_{t}}, \frac{K_{t}}{N_{t}}\right\} N_{t} \\
& c_{2}^{t}=\frac{r_{t+1} K_{t+1}}{(1-\delta) N_{t}} \\
& \quad+\min \left\{\frac{\theta_{t+1} k_{t+1}}{N_{t}}, \frac{N_{t+1}}{N_{t}} \cdot A\left(w_{t+1}, K_{t+1}, N_{t+1}\right)\right\} \\
& B\left(w_{t}, K_{t}, N_{t}\right)=n\left(E\left(c_{2}^{t} v^{\prime}\left(c_{2}^{t}\right)\right), w_{t}\right)
\end{aligned}
$$

where the expectation in (A10) is taken with respect to the distribution of $\left(w_{t+1}, N_{t+1}, \theta_{t+1}, r_{t+1}\right)$. The following proposition shows that the function $B(\cdot, \cdot, \cdot)$ defined in equation (A10) has similar properties to that of the function $A(\cdot, \cdot, \cdot)$.

Proposition 1: For $\underline{\mathrm{K}} \leqq \mathrm{K}_{\mathrm{t}} \leqq \overline{\mathrm{K}}$, $\underline{w} \leqq \mathrm{w}_{\mathrm{t}} \leq \overline{\mathrm{w}}, \underline{\mathrm{N}} \leqq \mathrm{N}_{\mathrm{t}} \leqq \overline{\mathrm{N}}$, we have

$$
B\left(w_{t}, K_{t}, N_{t}\right) \in\left[\frac{\underline{\theta} \underline{K}}{\bar{N}(1-\delta)}, \frac{\bar{\theta} \bar{K}}{\underline{N}(1-\delta)}\right] \text {. }
$$


Further, $B\left(w_{t}, K_{t}, N_{t}\right)$ is continuous in all arguments and nondecreasing in $\left(w_{t}, k_{t}\right)$.

Proof: Since $A(\cdot, \cdot, \cdot)$ is a continuous function, $K_{t+1}$ is also a continuous function of $\left(w_{t}, K_{t}, N_{t}\right)$. Since

$$
A\left(w_{t}, K_{t}, N_{t}\right) \varepsilon\left[\frac{\underline{\theta} \underline{K}}{\bar{N}(1-\delta)}, \frac{\bar{\theta} \bar{K}}{\underline{N}(1-\delta)}\right],
$$

we then have $\mathrm{K}_{t+1} \varepsilon[\underline{\mathrm{K}}, \overline{\mathrm{K}}]$. Therefore, $c_{2}^{t}$ is a continuous function of $\left(w_{t}, K_{t}, N_{t}\right)$. Thus, we have that $B(\cdot, \cdot, \cdot)$ is continuous. Since $A\left(w_{t}, K_{t}, N_{t}\right)$ is non-decreasing in $\left(w_{t}, k_{t}\right),\left(c_{2}^{t} V^{\prime}\left(c_{2}^{t}\right)\right)$ is also nondecreasing in $\left(w_{t}, K_{t}\right)$ by equation (3). Since $n\left(E_{t}\left(c_{2}^{t} V^{\prime}\left(c_{2}^{t}\right)\right), w_{t}\right)$ is non-decreasing in $\left(w_{t}, K_{t}\right)$, we have that $B(\cdot, \cdot, \cdot)$ is non-decreasing in its first two arguments.

$$
\begin{aligned}
& \text { Since } w_{t} \leqq \bar{w}, n(\cdot, \cdot) \leqq \bar{w} \text {, we have } \\
& \qquad B\left(w_{t}, K_{t}, N_{t}\right) \leqq \bar{w}=\frac{\underline{\theta} \delta \bar{K}}{(1-\delta) \bar{N}} \leqq \frac{\bar{\theta} \bar{k}}{(1-\delta) \underline{N}} .
\end{aligned}
$$

Since

$$
\frac{N_{t}(1-\delta) A\left(w_{t}, K_{t}, N_{t}\right)}{\theta_{t}} \geq \underline{K},
$$

we have $\mathrm{K}_{\mathrm{t}+1} \geqq \underline{\mathrm{K}}$. Also

$$
c_{2}^{t} \geq \frac{\underline{K} \underline{r}}{\vec{N}},
$$

so

$$
E_{t}\left(c_{2}^{t} V\left(c_{2}^{t}\right)\right) \geqq\left.\left(c_{2}^{t} V\left(c_{2}^{t}\right)\right)\right|_{c_{2}^{t}=\left(\frac{\underline{\underline{T}}}{\bar{N}}\right)} .
$$

Since $w_{t} \geqq \underline{w}$, and $n(\cdot, \cdot)$ is non-decreasing in both arguments, we 
have

$$
\begin{aligned}
& B\left(w_{t}, K_{t}, N_{t}\right)=n\left(E_{t}\left(c_{2}^{t} V^{\prime}\left(c_{2}^{t}\right)\right), w_{t}\right) \\
& \geq\left. n\left(c_{2}^{t} V^{\prime}\left(c_{2}^{t}\right), \underline{w}\right)\right|_{c_{2}^{t}=\left(\frac{\underline{\underline{r}}}{\bar{N}}\right)} \stackrel{\underline{\underline{K}} \underline{\theta}}{(1-\delta) \bar{N}}
\end{aligned}
$$

by (A7).

If we can show that the functions $A(\cdot, \cdot, \cdot)$ and $B(\cdot, \cdot, \cdot)$ exist such that $B\left(w_{t}, K_{t}, N_{t}\right) \equiv A\left(w_{t}, K_{t}, N_{t}\right)$ in equations $(A 8)-(A 10)$, then the associated functions

$$
\begin{aligned}
& h\left(w_{t}, k_{t}, N_{t}, \theta_{t}\right)=N_{t}(1-\delta) \max \left\{\frac{A\left(w_{t}, k_{t}, N_{t}\right)}{\theta_{t}}, \frac{k_{t}}{N_{t}}\right\} \\
& q\left(w_{t}, k_{t}, N_{t}, \theta_{t}\right)=\min \left\{\theta_{t}, \frac{A\left(w_{t}, k_{t}, N_{t}\right)}{\frac{k_{t}}{N_{t}}}\right\} \\
& K_{t+1}=h\left(w_{t}, k_{t}, N_{t}, \theta_{t}\right) \\
& P_{t}=q\left(w_{t}, k_{t}, N_{t}, \theta_{t}\right)
\end{aligned}
$$

solve the system (A1)-(A4). To establish this note that (A4) is easily verified. (A9) becomes

$$
\begin{aligned}
c_{2}^{t} & =\frac{r_{t+1} K_{t+1}}{N_{t}(1-\delta)} \\
& +\left(\frac{K_{t+1}}{N_{t}}\right) \cdot \min \left\{\theta_{t+1},\left(\frac{N_{t+1}}{K_{t+1}}\right) A\left(w_{t+1}, K_{t+1}, N_{t+1}\right)\right\} \\
c_{2}^{t} & =\frac{r_{t+1} K_{t+1}}{N_{t}(1-\delta)}+\frac{K_{t+1}}{N_{t}}\left(q\left(w_{t+1}, k_{t+1}, N_{t+1}\right)\right)
\end{aligned}
$$




$$
c_{2}^{t}=\frac{r_{t+1} K_{t+1}}{N_{t}(1-\delta)}+\frac{P_{t+1} K_{t+1}}{N_{t}}
$$

Also, we have

$$
\begin{aligned}
\frac{P_{t} K_{t+1}}{N_{t}(1-\delta)} & =\frac{q\left(w_{t}, K_{t}, N_{t}, \theta_{t}\right)}{(1-\delta) N_{t}} \cdot h\left(w_{t}, K_{t}, N_{t}, \theta_{t}\right) \\
& =A\left(w_{t}, K_{t}, N_{t}\right) \equiv B\left(w_{t}, K_{t}, N_{t}\right) \\
& =n\left(E_{t}\left(c_{2}^{t} V^{\prime}\left(c_{2}^{t}\right)\right), w_{t}\right)
\end{aligned}
$$

by $(\mathrm{Al0})$. Now by the definition of $n(\cdot, \cdot)$ we have

$$
\left[\frac{P_{t} K_{t+1}}{(1-\delta) N_{t}}\right] U^{\prime}\left(w_{t}-\left(\frac{P_{t} K_{t+1}}{N_{t}(1-\delta)}\right)\right)=E_{t}\left(c_{2}^{t} V^{\prime}\left(c_{2}^{t}\right)\right) \text {. }
$$

Hence, equations (Al) - (A4) hold.

The problem is then reduced to finding a fixed point of the mapping $A\left(w_{t}, K_{t}, N_{t}\right) \rightarrow B\left(w_{t}, K_{t}, N_{t}\right)$ defined in $(A 8)-(A 10)$. Our strategy will be as follows. We will define a class of functions with certain properties. Next we will define a mapping on this class of functions similar to the mapping of $A\left(w_{t}, k_{t}, N_{t}\right) \rightarrow B\left(w_{t}, k_{t}, N_{t}\right)$ defined in $(A 8)-(A 10)$. We then show that such a mapping has a fixed point. Lastly we show that this fixed point implies the existence of functions $A(\cdot, \cdot, \cdot)$ and $B(\cdot, \cdot, \cdot)$ such that equations (A8) - (A10) hold identically with $A\left(w_{t}, k_{t}, N_{t}\right) \equiv B\left(w_{t}, k_{t}, N_{t}\right)$. This in turn implies that this is an equilibrium for the economy.

Let $\underline{x}=\ln \underline{K}, \bar{x}=\ln \bar{K}$. Define 
$S=\left\{\begin{aligned} g(w, X, N) & \begin{array}{r}g(\cdot, \cdot, \cdot):[\underline{w}, \bar{w}] \times[\underline{X}, \bar{X}] \times[\underline{N}, \bar{N}] \\ g(\cdot, \cdot, \cdot) \text { is continuous in all arguments and } \\ \text { non-decreasing in its first two arguments. } \\ \left|g(w, X, N)-g\left(w^{\prime}, X, N\right)\right| \leqq D_{1}\left|w-w^{\prime}\right| \\ \left|g(w, X, N)-g\left(w, X^{\prime}, N\right)\right| \leqq\left|X-X^{\prime}\right| \\ \left|g(w, X, N)-g\left(w, X, N^{\prime}\right)\right| \leqq D_{2}\left|N-N^{\prime}\right|\end{array} .\end{aligned}\right.$

Define the metric on $S$ to be

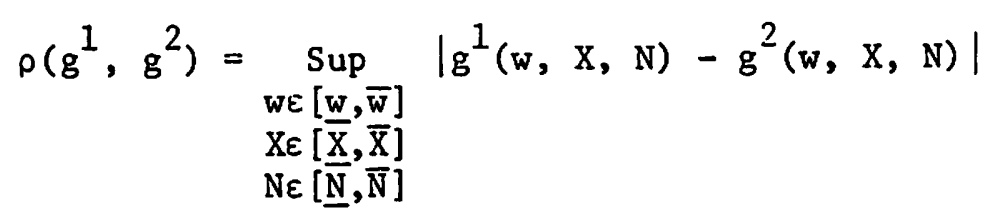

for $g^{1}, g^{2} \varepsilon S$.

Define

$$
\begin{aligned}
& Y=\ln (1-\delta)+\ln (N)+\max \{g(w, X, N)-\ln (\theta), X-\ln (N)\} \\
& c_{2}=\frac{r^{\prime} e^{Y}}{N(1-\delta)}+\min \left\{\frac{\theta^{\prime} e^{Y}}{N},\left(\frac{N^{\prime}}{N}\right) \exp \left(g\left(w^{\prime}, Y, N^{\prime}\right)\right)\right\} \\
& \tilde{g}(w, X, N)=\ln \left\{n\left(E\left(c_{2} V^{\prime}\left(c_{2}\right)\right), w\right)\right\} .
\end{aligned}
$$

Proposition 2: The set S is compact and convex.

Proof: The set $\mathrm{S}$ is bounded because

$$
|g(w, X, N)| \leqq \ln \left(\frac{\bar{\theta} \bar{K}}{\underline{N}(1-\delta)}\right) \text { for all } g \in S,
$$


and $(w, X, N) \varepsilon[\underline{w}, \bar{w}] \times[\underline{x}, \bar{x}] \times[\underline{N}, \bar{N}]$.

To show that the set of functions $S$ is equicontinuous, pick any $\varepsilon>0$, and choose $\mu>0, \mu<\varepsilon /\left(I+D_{1}+D_{2}\right)$. Now if

$$
\left|w-w^{\prime}\right|+\left|X-X^{\prime}\right|+\left|N-N^{\prime}\right|<\mu
$$

we have

$$
\begin{aligned}
& \left|g(w, X, N)-g\left(w^{\prime}, X^{\prime}, N^{\prime}\right)\right| \\
\leqq & \left|g(w, X, N)-g\left(w^{\prime}, X, N\right)\right| \\
& +\mid g\left(w^{\prime}, X, N\right)-g\left(w^{\prime}, X^{\prime}, N \mid\right. \\
& \quad+\left|g\left(w^{\prime}, X^{\prime}, N\right)-g\left(w^{\prime}, X^{\prime}, N^{\prime}\right)\right| \\
\leqq & D_{1}\left|w-w^{\prime}\right|+\left|X-X^{\prime}\right|+D_{2}\left|N-N^{\prime}\right| \\
\leqq & \left.\left(1+D_{1}+D_{2}\right)\left(\mid w-w^{\prime}\right)|+| X-X^{\prime}|+| N-N^{\prime} \mid\right) \\
\leqq & \left(1+D_{1}+D_{2}\right) \mu<\varepsilon .
\end{aligned}
$$

Therefore, the functions of the set $S$ are equicontinuous. It then follows from the theorem of Arzela-Ascoli that the set $S$ is compact (see [10], page 22).

Let $g^{1}(\cdot, \cdot, \cdot)$ and $g^{2}(\cdot, \cdot, \cdot) \in S$. Then for $\lambda \varepsilon[0,1]$, $\lambda \mathrm{g}^{1}(\cdot, \cdot, \cdot)+(1-\lambda) \mathrm{g}^{2}(\cdot, \cdot, \cdot)$ is continuous, non-decreasing in its first two arguments and

$$
\varepsilon\left[\ln \left(\frac{\underline{\theta} \underline{K}}{\overline{\mathrm{N}}(1-\delta)}\right), \ln \left(\frac{\bar{\theta} \overline{\mathrm{K}}}{\underline{\hat{N}(1-\delta)}}\right)\right] .
$$

We then have 


$$
\begin{aligned}
& \mid \lambda g^{1}(w, X, N)+(1-\lambda) g^{2}(w, X, N)-\lambda g^{1}\left(w^{\prime}, X, N\right) \\
& -(1-\lambda) g^{2}\left(w^{\prime}, X, N\right) \\
& \leqq \lambda\left|g^{1}(w, X, N)-g^{1}\left(w^{\prime}, X, N\right)\right|+(1-\lambda) \mid g^{2}(w, X, N) \\
& -g^{2}\left(w^{\prime}, x, N\right) \\
& \leqq\left(\lambda D_{1}+(1-\lambda) D_{1}\right)\left|w-w^{\prime}\right|=D_{1}\left|w-w^{\prime}\right| \text {. }
\end{aligned}
$$

Also,

$$
\begin{aligned}
\mid \lambda g^{1}(w, X, N)+(1-\lambda) g^{2}(w, X, N) & -\lambda g^{1}\left(w, X^{\prime}, N\right) \\
& -(1-\lambda) g^{2}\left(w, X^{\prime}, N\right) \mid \\
\leqq & -(1-\lambda) \mid g^{2}(w, X, N) \\
& -g^{2}\left(w, X^{\prime}, N\right) \mid \\
\leqq & (\lambda+(1-\lambda))\left|X-X^{\prime}\right|=\left|X-X^{\prime}\right| .
\end{aligned}
$$

And finally,

$$
\begin{aligned}
\mid \lambda g^{1}(w, X, N)+(1-\lambda) g^{2}(w, X, N) & -\lambda g^{1}\left(w, X, N^{\prime}\right) \\
& -(1-\lambda) g^{2}\left(w, X, N^{\prime}\right) \mid \\
\leqq & \left(\lambda D_{2}+(1-\lambda) D_{2}\right)\left|N-N^{\prime}\right|=D_{2}\left|N-N^{\prime}\right| .
\end{aligned}
$$

Therefore, $\lambda g^{1}(\cdot, \cdot, \cdot)+(I-\lambda) g^{2}(\cdot, \cdot, \cdot) \varepsilon s$, and so the set

$S$ is convex.

Proposition 3: $\tilde{\mathrm{g}}(\cdot, \cdot, \cdot) \varepsilon \mathrm{S}$.

Proof: Making the transformations

$$
\begin{aligned}
& K_{t}=e^{X}, K_{t+1}=e^{Y} \\
& A\left(w_{t}, K_{t}, N_{t}\right)=\exp \left(g\left(w_{t}, \ln \left(K_{t}\right), N_{t}\right)\right) \\
& B\left(w_{t}, K_{t}, N_{t}\right)=\exp \left(\tilde{g}\left(w_{t}, \ln \left(K_{t}\right), N_{t}\right)\right)
\end{aligned}
$$


and so $(\mathrm{Al} 15)-(\mathrm{Al})$ reduce to $(\mathrm{A} 8)-(\mathrm{A} 10)$. Application of Proposition

1 shows that $\tilde{g}(w, X, N)$ is continuous, non-decreasing in $(w, X)$, and

$$
\ln \left(\frac{\underline{\theta} \underline{K}}{\bar{N}(1-\delta)}\right) \leqq \tilde{g}(w, x, N) \leqq \ln \left(\frac{\bar{\theta} \bar{K}}{N(1-\delta)}\right) .
$$

Hence, we need only verify that

$$
\begin{aligned}
& \left|\tilde{g}(w, x, N)-\tilde{g}\left(w^{\prime}, x, N\right)\right| \leqq D_{1}\left|w-w^{\prime}\right| \\
& \left|\tilde{g}(w, x, N)-\tilde{g}\left(w, x^{\prime}, N\right)\right| \leqq\left|x-x^{\prime}\right| \\
& \left|\tilde{g}(w, x, N)-\tilde{g}\left(w, x, N^{\prime}\right) \leqq D_{2}\right| N-N^{\prime} \mid .
\end{aligned}
$$

By virtue of the Lipshitz conditions imposed upon $g(\cdot, \cdot, \cdot)$, we know that $g(\cdot, \cdot, \cdot)$ is differentiable almost everywhere. Hence, from (Al5) we have that $Y$ is differentiable a.e. with respect to ( $W, X, N)$, and from (Al6) we have that $c_{2}$ is a.e. differentiable with respect to $\left(w^{\prime}, Y, N^{\prime}\right)$. Hence, $E\left(c_{2} V^{\prime}\left(c_{2}\right)\right)$ is a.e. differentiable with respect to $(w, X, N)$. Finally, since $n(\cdot, \cdot)$ is differentiable, we have that $\tilde{g}(w, X, N)$ is differentiable a.e.

Now (Al5) implies

$$
\begin{aligned}
& 0 \leq \frac{\partial Y}{\partial W} \leq D_{1} \\
& 0 \leq \frac{\partial Y}{\partial X} \leq 1 \\
& -D_{2} \leq\left(\frac{1}{N}\right)-D_{2} \leq \frac{\partial Y}{\partial N} \leq\left(\frac{1}{N}\right)+D_{2} .
\end{aligned}
$$

Considering where $\frac{\theta^{\prime} e^{y}}{N}<\left(\frac{N^{\prime}}{N}\right) \exp \left(g\left(w^{\prime}, Y, N^{\prime}\right)\right)$, we have

$c_{2}=\frac{e^{Y}}{N}\left[\frac{r^{\prime}}{(1-\delta)}+\theta^{\prime}\right]$ and consequently 


$$
\left(\frac{1}{c_{2}}\right)\left(\frac{\partial c_{2}}{\partial Y}\right)=1 \text {. }
$$

Also,

$$
\left(\frac{1}{c_{2}}\right)\left(\frac{\partial c_{2}}{\partial N}\right)=\frac{-1}{N}+\frac{\partial Y}{\partial N} .
$$

In the region where $\frac{\theta^{\prime} e^{Y}}{N}>\left(\frac{N^{\prime}}{N}\right) \exp \left(g\left(w^{\prime}, Y, N^{\prime}\right)\right)$ we have $c_{2}=\frac{r^{\prime} e^{Y}}{(1-\delta) N}+\left(\frac{N^{\prime}}{N}\right) \exp \left(g\left(w^{\prime}, Y, N^{\prime}\right)\right)$, and consequently,

$$
\left(\frac{1}{c_{2}}\right)\left(\frac{\partial c_{2}}{\partial Y}\right)=\frac{\left[\frac{r^{\prime} e^{Y}}{N(1-\delta)}+g_{2}\left(\frac{N^{\prime}}{N}\right) \exp \left(g\left(w^{\prime}, Y, N^{\prime}\right)\right)\right]}{\left[\frac{r^{\prime} e^{Y}}{N(1-\delta)}+\left(\frac{N^{\prime}}{N}\right) \exp \left(g\left(w^{\prime}, Y, N^{\prime}\right)\right)\right]} \leqq 1
$$

Also,

$$
\left(\frac{1}{c_{2}}\right)\left(\frac{d c_{2}}{d N}\right)=\left(\frac{-1}{N}\right)+\frac{\left[\frac{r^{\prime} e^{Y}}{N(1-\delta)}+g_{2}\left(\frac{N^{\prime}}{N}\right) \exp \left(g\left(w^{\prime}, Y, N^{\prime}\right)\right)\right]}{\left[\frac{r^{\prime} e^{Y}}{N(1-\delta)}+\left(\frac{N^{\prime}}{N}\right) \exp \left(g\left(w^{\prime}, Y, N^{\prime}\right)\right)\right]} \frac{\partial Y}{\partial N} .
$$

Combining (A18), (A21), and (A23) we have

$$
0 \leq\left(\frac{1}{c_{2}}\right)\left(\frac{\partial c_{2}}{\partial Y} \frac{\partial Y}{\partial w}\right) \leq D_{1} .
$$

Combining (A19), (A21), and (A23) we have

$$
0 \leq\left(\frac{1}{c_{2}}\right)\left(\frac{\partial c_{2}}{\partial Y} \frac{\partial Y}{\partial X}\right) \leq 1 .
$$

Combining (A20), (A22), and (A24) we hàve 


$$
-\left\{\frac{1}{\underline{N}}+D_{2}\right\} \leq\left(\frac{1}{c_{2}}\right)\left(\frac{d c}{d N}\right) \leq D_{2} .
$$

We can now write

$$
\begin{aligned}
\tilde{g}_{1}(w, X, N) & =\left\{\frac{E\left(c_{2} V^{\prime}\left(c_{2}\right)\right) n_{1}}{n}\right\} \\
& \cdot\left\{\frac{E\left\{\left[c_{2} V^{\prime}\left(c_{2}\right)\right] \frac{c_{2}}{c_{2} V^{\prime}\left(c_{2}\right)} \frac{\partial\left(c_{2} V^{\prime}\left(c_{2}\right)\right)}{\partial c_{2}} \frac{1}{c_{2}} \frac{\partial c_{2}}{\partial Y} \frac{\partial Y}{\partial w}\right\}}{E\left[c_{2} V^{\prime}\left(c_{2}\right)\right.}\right\} \\
& +\left\{\frac{w \eta_{2}}{\eta}\right\}\left(\frac{1}{W}\right) .
\end{aligned}
$$

From (A6), (A25), and equation (3) we have

$$
0 \leq \tilde{g}_{1}(w, x, N) \leq\left(\alpha D_{1}+\frac{1}{\underline{w}}\right) .
$$

By choosing $D_{1}>\frac{1}{\underline{w}(1-\alpha)}$ we have that

$$
0 \leq \tilde{g}_{1}(w, X, N) \leq D_{1}
$$

Similarly,

$$
\begin{aligned}
\tilde{g}_{2}(w, X, N)= & \left\{\frac{E\left(c_{2} V^{\prime}\left(c_{2}\right)\right) n_{1}}{n}\right\} \\
& \cdot\left\{\frac{E\left\{\left[c_{2} V^{\prime}\left(c_{2}\right)\right]\left\{\frac{c_{2}}{c_{2} V^{\prime}\left(c_{2}\right)} \frac{\partial\left(c_{2} V^{\prime}\left(c_{2}\right)\right)}{\partial c_{2}}\right\} \frac{1}{c_{2}} \frac{\partial c_{2}}{\partial Y} \frac{\partial Y}{\partial X}\right\}}{E\left(c_{2} V^{\prime}\left(c_{2}\right)\right)}\right\}
\end{aligned}
$$

By equations (3), (A5), and (A26) we have

$$
0 \leq \tilde{g}_{2}(w, x, N) \leq 1
$$

Finally, 


$$
\begin{aligned}
\tilde{g}_{3}(w, X, N)= & \left\{\frac{E\left(c_{2} V^{\prime}\left(c_{2}\right)\right) n_{1}}{n}\right\} \\
& \cdot\left\{\frac{E\left\{\left[c_{2} V^{\prime}\left(c_{2}\right)\right]\left\{\frac{c_{2}}{c_{2} V^{\prime}\left(c_{2}\right)} \frac{\left.\partial c_{2} V^{\prime}\left(c_{2}\right)\right)}{\partial c_{2}}\right\} \frac{1}{c_{2}} \frac{d c_{2}}{d N}\right\}}{E\left(c_{2} V^{\prime}\left(c_{2}\right)\right)}\right\} .
\end{aligned}
$$

From equations ( 3 ), (A5), and (A27) we have

$$
-\alpha\left\{\frac{1}{\underline{N}}+D_{2}\right\} \leq \tilde{g}_{3}(w, x, N) \leq \alpha D_{2}
$$

By choosing $D_{2} \leq\left[\frac{\alpha}{\underline{N}(1-\alpha)}\right]$ we have

$$
-D_{2} \leq \tilde{g}_{3}(w, X, N) \leq D_{2}
$$

Therefore, we conclude that

$$
\begin{aligned}
& \left|\tilde{g}(w, x, N)-\tilde{g}\left(w^{\prime}, x, N\right)\right| \leq D_{1}\left|w-w^{\prime}\right| \\
& \left|\tilde{g}(w, x, N)-\tilde{g}\left(w, x^{\prime}, N\right)\right| \leq\left|x-x^{\prime}\right| \\
& \left|\tilde{g}(w, x, N)-\tilde{g}\left(w, x, N^{\prime}\right)\right| \leq D_{2}\left|N-N^{\prime}\right| .
\end{aligned}
$$

Therefore, $\cdot \tilde{g}(\cdot, \cdot, \cdot) \in S$ as was to be shown. Now equations (A15) - (A17) define a mapping $\mathrm{T}: \mathrm{S} \rightarrow \mathrm{S}$.

Proposition 4: The mapping $\mathrm{T}: \mathrm{S} \rightarrow \mathrm{S}$ is continuous.

Proof: Let $g^{n}(\cdot, \cdot, \cdot) \rightarrow g^{*}(\cdot, \cdot, \cdot)$ with $g^{n}(\cdot, \cdot, \cdot) \in S$ and let

$$
\begin{aligned}
& Y^{n}(w, X, N)=\ln (1-\delta)+\ln (N)+\max \left\{g^{n}(w, X, N)-\ln (\theta), X-\ln (N)\right\} \\
& Y *(w, X, N)=\ln (1-\delta)+\ln (N)+\max \{g *(w, X, N)-\ln (\theta), X-\ln (N)\}
\end{aligned}
$$




$$
\begin{aligned}
c_{2_{n}}(w, X, N) & =\frac{r^{\prime} \exp \left(Y^{n}(w, X, N)\right)}{N(1-\delta)} \\
& +\min \left\{\frac{\theta^{\prime} \exp \left(Y^{n}(w, X, N)\right)}{N},\left(\frac{N^{\prime}}{N}\right) \exp \left(g^{*}\left(w^{\prime}, Y^{n}(w, X, N), N^{\prime}\right)\right)\right\} \\
c_{2 *}(w, X, N) & =\frac{r^{\prime} \exp \left(Y^{*}(w, X, N)\right)}{N(1-\delta)} \\
& +\min \left\{\frac{\theta^{\prime} \exp (Y *(w, X, N))}{N},\left(\frac{N^{\prime}}{N}\right) \exp \left(g^{*}\left(w^{\prime}, Y^{*}(w, X, N), N^{\prime}\right)\right)\right\} \\
\tilde{g}^{n}(w, X, N) & =\ln n\left(E\left(c_{2} V^{\prime}\left(c_{2}\right)\right), w\right) \\
\tilde{g}^{*}(w, X, N)= & \ln n\left(E\left(c_{2} V^{\prime}\left(c_{2}\right)\right), w\right) .
\end{aligned}
$$

Then since $g^{n}(\cdot, \cdot, \cdot) \rightarrow g^{*}(\cdot, \cdot, \cdot)$ it follows that

$\mathrm{Y}^{\mathrm{n}}(\cdot, \cdot, \cdot) \rightarrow \mathrm{Y} *(\cdot, \cdot, \cdot)$, and $\mathrm{c}_{2_{\mathrm{n}}}(\cdot, \cdot, \cdot) \rightarrow \mathrm{c}_{2}(\cdot, \cdot, \cdot)$, and hence $\tilde{g}^{\mathrm{n}}(\cdot, \cdot, \cdot) \rightarrow \mathrm{g} *(\cdot, \cdot, \cdot)$. Hence, the mapping is continuous.

Proposition 5: There exists a fixed point for the mapping $T$. That is, there exists a function $\mathrm{g}^{*}(\cdot, \cdot, \cdot) \varepsilon \mathrm{S}$ such that $\mathrm{Tg} *=\mathrm{g}^{*}$.

Proof: Since the set $S$ is compact and convex (Proposition 2) and the mapping $T$ is continuous (Proposition 4), the result follows (see [10] page 640).

Let $g^{*}(w, x, N)$ be the fixed point of the mapping $T$. Define

$$
\begin{aligned}
& A^{*}\left(w_{t}, K_{t}, N_{t}\right)=\exp \left(g *\left(w_{t}, \ln \left(K_{t}\right), N_{t}\right)\right) \\
& h\left(w_{t}, K_{t}, N_{t}, \theta_{t}\right)=N_{t}(1-\delta) \max \left\{\frac{A^{*}\left(w_{t}, K_{t}, N_{t}\right)}{\theta_{t}}, \frac{K_{t}}{N_{t}}\right\} \\
& q\left(w_{t}, K_{t}, N_{t}, \theta_{t}\right)=\min \left\{\theta_{t}, A *\left(w_{t}, K_{t}, N_{t}\right)\left(\frac{N_{t}}{K_{t}}\right)\right\}
\end{aligned}
$$


The latter two equations define the aforementioned functions which solves the system (A1) - (A4). 


\section{APPENDIX B}

Throughout this appendix, we carry through all assumptions made in Appendix A. In addition, we assume $0<\alpha<(1 / 2)$.

Next we rewrite the mapping of $(\mathrm{Al} 15)-(\mathrm{Al} 7)$ as

$$
\operatorname{Tg}=\ln \left[n\left(E\left(c_{2}(g) V^{\prime}\left(c_{2}(g)\right)\right), w\right)\right]
$$

where

$$
c_{2}(g)=\frac{r^{\prime} e^{Y}}{N(1-\delta)}+\min \left\{\frac{\theta^{\prime} e^{Y}}{N},\left(\frac{N^{\prime}}{N}\right) \exp \left(g\left(w^{\prime}, Y, N^{\prime}\right)\right)\right\},
$$

and

$$
\mathrm{Y}=\ln (1-\delta)+\ln (\mathrm{N})+\max \{\mathrm{g}(\mathrm{w}, \mathrm{X}, \mathrm{N})-\ln (\theta), \mathrm{X}-\ln (\mathrm{N})\}
$$

Note that

$$
\frac{\partial Y}{\partial g} \leqq 1
$$

If

$$
c_{2}(g)=\frac{e^{Y}}{N}\left[\frac{r^{\prime}}{(1-\delta)}+\theta^{\prime}\right]
$$

then

$$
\left(\frac{1}{c_{2}(g)}\right) \frac{\partial c_{2}(g)}{\partial Y}=1
$$

and if

$$
c_{2}(g)=\frac{r^{\prime} e^{Y}}{N(I-\delta)}+\frac{N^{\prime}}{N} \exp \left(g\left(w^{\prime}, Y, N^{\prime}\right)\right)
$$

then

$$
\left(\frac{1}{c_{2}(g)}\right)\left(\frac{\partial c_{2}(g)}{\partial Y}\right) \leq 1 .
$$

Then 


$$
\begin{aligned}
& \left(\frac{1}{c_{2}(z)}\right)\left(\frac{d c_{2}(z)}{d z}\right)=\left(\frac{1}{c_{2}(z)}\right)\left(\frac{\partial c_{2}(z)}{\partial Y} \frac{\partial Y}{\partial z}\right)+\left(\frac{\partial c_{2}(z)}{\partial z}\right) \\
& \leqq\left(1+\frac{\left(\frac{N^{\prime}}{N}\right) \exp (z)}{\left(\frac{r^{\prime} e^{Y}}{N(1-\delta)}+\left(\frac{N^{\prime}}{N}\right) \exp (z)\right)}\right) \leqq 2 .
\end{aligned}
$$

Now we may write, for $f, g \in S$

$$
\begin{aligned}
& |\mathrm{Tg}-\mathrm{Tf}| \\
= & \mid \ln \left(n\left(E\left(c_{2}(g) V^{\prime}\left(c_{2}(g)\right)\right), w\right)-\ln \left(n\left(E\left(c_{2}(f) V^{\prime}\left(c_{2}(f)\right)\right), w\right)\right) \mid .\right.
\end{aligned}
$$

Also,

$$
\begin{aligned}
& \frac{\partial \ln \left[n\left(E\left(c_{2}(z) V^{\prime}\left(c_{2}(z)\right)\right), w\right)\right]}{\partial w} \\
& =\left\{\frac{E\left(c_{2}(z) V^{\prime}\left(c_{2}(z)\right)\right) n_{1}}{n}\right\} \\
& \text { - }\left\{\frac{E\left\{\left(c_{2}(z) V^{\prime}\left(c_{2}(z)\right)\right)\left\{\frac{c_{2}(z)}{\left.c_{2}(z) V^{\prime}\left(c_{2}(z)\right)\right)} \frac{\partial\left(c_{2}(z) V^{\prime}\left(c_{2}(z)\right)\right)}{\partial c_{2}(z)}\right\} \frac{1}{c_{2}(z)} \frac{d c_{2}(z)}{d z}\right\}}{E\left(c_{2}(z) V^{\prime}\left(c_{2}(z)\right)\right)}\right\}
\end{aligned}
$$

The first term in parentheses is between 0 and 1 by equation (AS) of Appendix A. The second term in parentheses is positive and strictly less than one. Hence, by the mean value theorem we may write (B1) as

$$
|\mathrm{Tg}-\mathrm{Tf}|<|\mathrm{g}-\mathrm{f}|
$$

Since $S$ is compact, it can be shown that $T$ has a unique fixed point (see $[10]$, page 629, Theorem 2).

A comment is now due concerning the uniqueness of such equilibria. Consider the class of utility functions of the form. 


$$
U\left(c_{1}^{t}\right)+V\left(c_{2}^{t}\right)=\frac{\left(c_{1}^{t}\right)^{1-A}-1}{1-A}+\frac{\left(c_{2}^{t}\right)^{1-B}-1}{1-B}
$$

where $A, B \geq 0$. Note that

$$
\lim \left(\frac{\left(c_{1}^{t}\right)^{1-A}-1}{1-A}\right)=\ln \left(c_{1}^{t}\right) .
$$

$A$ and $B$ are the Arrow-Pratt measures of relative risk aversion. Equations (3) and (4) effectively assumed $0 \leq A<1$ and $0 \leq B \leq 1$. In this appendix we have shown that if $0 \leq B<(1 / 2)$, the equilibrium would be unique. We conjecture that for utility functions which exhibit higher levels of risk aversion, one is likely to find that there will be a multiplicity of such stationary equilibria. One may see this by using the utility function (B2) in equation (10). This equation then becomes a polynomial in $\mathrm{P}_{t}$, and solving the system for equilibrium values entails finding the zeroes of such a polynomial. However, as the measure of relative risk aversion becomes greater, that is, as B becomes larger, the degree of this polynomial becomes higher and, hence, the more likely it will be that, for utility functions of the form (B2) which exhibit a high degree of risk aversion, there may exist more than one stationary equilibrium. 


\section{FOOTNOTES}

${ }^{1}$ Grossman and Shiller used annual data on nondurable and real consumption and annual average deflated Standard and Poor's Composite Stock Price Index. Hansen and Singleton used monthly real nondurable consumption expenditures and various deflated monthly composite indices of stock on the New York Stock Exchange. With these data, Hansen and Singleton obtained estimates of A in equation (2), whereas Grossman and Shiller undertook a parameter search of a value of A which would "closely" mimic the time series of stock prices.

${ }^{2}$ It is not critical that the agents live only two periods. This assumption is used to make the model analytically tractable and because it does not detract from its interesting features.

3 This will preclude the possibility of risk-sharing arrangements between the young and old at time $(t)$.

${ }^{4}$ The proofs of Appendices A and B can easily be modified to accommodate more complicated distributions of these variables.

${ }^{5}$ Annual data for these computations were taken from the National Income and Product Accounts. The data were in real terms and were then converted to per-capita terms and detrended. The above statistics were then computed from the resulting series.

6 Data for this statistic were obtained from the Kendrick-Kuznets series.

${ }^{7}$ Ha11 uses quarter $1 y$ data. 


\section{REFERENCES}

[1] Aiyagari, S. R. "Putty-Clay Capital in Stochastic Overlapping Generations Models". Unpublished Ph.D. dissertation, University of Minnesota (1981).

[2] Brock, William A. "Asset Prices in a Production Economy," in The Economics of Information and Uncertainty, ed. J. J. McCall. Chicago: University of Chicago Press (1982).

[3] Danthine, J. P. "Martingale, Market Efficiency and Commodity Prices". European Economic Review 10 (October 1977): 1-17.

[4] Fama, Eugene F. "Efficient Capital Markets : A Review of Theory and Empirical Work". Journal of Finance 25 (May 1970): 387-417.

[5] Grossman, Sanford F., and Shiller, Robert J. "The Determinants of the Variability of Stock Market Prices". American Economic Review 71 (May 1981): 222-227.

[6] Ha11, Robert E. "Stochastic Implications of the Life Cycle-Permanent Income Hypothesis: Theory and Evidence". Journal of Political Economy 86 (December 1978): 971-987.

[7] Hansen, L. Po, and Singleton, K. J. "Econometric Implications of the Intertemporal Capital Asset Pricing Model". GSIA Carnegie-Mellon University Working Paper (September 1981).

[8] Hansen, L. P., and Singleton, K. J. "Stochastic Consumption, Risk Aversion, and the Temporal Behavior of Stock Market Returns". CarnegieMellon University Working Paper, revised (April 1982)。

[9] Huffman, Gregory W. "An Overlapping Generations Model of Asset Pricing"。 Unpublished Ph.D. dissertation, University of Minnesota (1983).

[10] Kantorovich, I. V., and Akilov, G. P. Functional Analysis in Normed Spaces (translated from the Russian by D. E. Brown and edited by A. P. Robertson). New York: Macmillan (1964).

[11] Kleidon, A. W. "Bias in Small Sample Tests of Stock Price Rationality". University of Chicago Graduate School of Business Working Paper, revised (May 1982).

[12] Kleidon, A. W. "Variance Bounds in a Simple Model of Asset Pricing: A Comment". University of Chicago Graduate School of Business Working Paper, revised (May 1982)。

[13] LeRoy, Stephen F. "Risk Aversion and the Martingale Property of Stock Prices". International Economic Review 14 (July 1973): 436-446.

[14] LeRoy, Stephen F. "Expectations Models of Asset Prices : A Survey of Theory". Journal of Finance 37 (March 1982): 185-217. 
[15] LeRoy, Stephen F. "Nominal Prices and Interest Rates in General Equilibrium: Endowment Shocks"。 University of California at Santa Barbara Working Paper (March 1982).

[16] LeRoy, Stephen F., and LaCivita, C. J. "Risk Aversion and the Dispersion of Asset Prices". Journal of Business 92 (October 1981): 535-547.

[17] LeRoy, Stephen F。, and Porter, Richard 0. "The Present-Value Relation: Tests on Implied Variance Bounds"。 Econometrica 49 (May 1981): 555-574.

[18] Lucas, Robert E., Jr. "Asset Prices in an Exchange Economy". Econometrica 46 (November 1978): 1429-1445.

[19] Malkie1, B. G., von Furstenberg, G. M., and Watson, H. S. "Expectations, Tobin's q, and Industry Investment". Journal of Finance 34 (1979): 549-561.

[20] Merton, R. C. "An Intertemporal Capital Asset Pricing Mode1". Econometrica 41 (September 1973): 867-887.

[21] Michener, Ronald W. "Variance Bounds in a Simple Model of Asset Pricing". Journal of Political Economy 90 (February 1982): 166-175.

[22] Prescott, Edward D., and Mehra, Rajnish. "A Test of the Intertemporal Asset Pricing Mode1"。 Federal Reserve Bank of Minneapolis, Staff Report $\$ 81$ (1982).

[23] Ross, S。 Ao "The Arbitrage Theory of Capital Asset Pricing"。 Journal of Economic Theory 13 (December 1976): 341-349。

[24] Sargent, Thomas J. "Tobin's $q$ ' and the Rate of Investment in General Equilibrium". Federal Reserve Bank of Minneapolis, Staff Report $\$ 40$ (April 1979)。

[25] Shiller, R。 Jo "The Use of Volatility Measures in Assessing Market Efficiency". NBER Working Paper 565 (October 1980).

[26] Shiller, R. J. "Do Stock Prices Move Too Much to be Justified by Subsequent Changes in Dividends?" American Economic Review 71 (June 1981): 421-436.

[27] Shiller, R. J. "Consumption, Asset Markets and Macroeconomic Fluctuations". NBER Working Paper 838 (January 1982). [28] Shiller, R。 J。 "Stock Market Prices, Interest Rates and the Business Cycle".
Yale Working Paper (May 1982).

[29] Sims, Christopher A. "Martingale-Like Behavior of Prices". NBER Working Paper 489, revised (February 1980)。

[30] Tobin, James。 "A General Equilibrium Approach to Monetary Theory"。 Journal of Money, Credit, and Banking 1 (February 1969): 15-29.

[31] Wallace, Neil. "The Overlapping Generations Model of Fiat Money," in Models of Monetary Economies, eds. Jo H. Kareken and N. Wallace. Minneapolis: Federal Reserve Bank of Minneapolis (1980). 